\section{Building a Sustainable National Infrastructure to Expand Research Mentor Training}

\author{
Kimberly C. Spencer, ${ }^{\dagger *}$ Melissa McDaniels, ${ }^{*}$ Emily Utzerath, ${ }^{\dagger}{ }^{\dagger}$ enna Griebel Rogers, ${ }^{\dagger}$ \\ Christine A. Sorkness, ${ }^{\dagger}$ Pamela Asquith, $\|$ and Christine Pfund ${ }^{\dagger} \$$ \\ ${ }^{\dagger}$ Institute for Clinical and Translational Research, "\$isconsin Center for Education Research, and \\ "Department of Obstetrics and Gynecology, University of Wisconsin-Madison, Madison, \\ WI 53705; 'Graduate School and Postdoctoral Office, Michigan State University, East Lansing, \\ MI 48824
}

\begin{abstract}
An evidence-based research mentor training (RMT) curricular series has been shown to improve the knowledge and skills of research mentors across disciplines and career stages. A train-the-trainer model was used in the context of several targeted approaches aimed at sustainability to support national dissemination of RMT and expand the network of facilitators prepared to implement the curricula. These infrastructure elements included 1) an expansion initiative to increase the number of trained facilitators able to deliver train-thetrainer workshops nationwide; 2 ) adaptation of RMT curricula for multiple audiences and career stages to increase accessibility; 3) implementation resources to support facilitators and help them overcome implementation barriers; and 4) standardized evaluation of training. This approach to dissemination and implementation has resulted in the preparation of nearly 600 trained facilitators, a large percentage of whom have implemented mentor training for more than $\mathbf{4 0 0 0}$ graduate student, junior faculty, and senior faculty mentors. Implications for and challenges to building and sustaining the national dissemination of RMT are discussed.
\end{abstract}

\section{INTRODUCTION}

Quality mentoring is an important contributor to success of researchers across all disciplines and career stages. It has been linked to enhanced trainee productivity, research self-efficacy, and career satisfaction (reviewed in Pfund et al. 2016; National Academies of Sciences, Engineering, and Medicine, 2017). Effective mentoring relationships have been shown to also influence the confidence of trainees' ability to successfully conduct research, which is a key predictor of persistence in science, technology, engineering, and mathematics (STEM; Byars-Winston et al., 2015). Mentors themselves also benefit from effective mentoring relationships, reporting an increase in productivity, a sense of fulfillment through knowledge and skill sharing, and increased self-awareness (Dolan and Johnson, 2009). Despite mentoring's positive impact, not all mentoring relationships are equally effective. In fact, students from historically underserved backgrounds report receiving less mentoring than their nonminority peers (Helm et al., 2000; Thomas, 2001; Morzinski and Fisher, 2002; Ginther et al., 2011; Beech et al., 2013). Unfortunately, most mentors do not receive training on how to optimize their mentoring relationships (Keyser et al., 2008; Silet et al., 2010; Pfund et al., 2015).

The need for more equitable access to quality mentoring has prompted many agencies, academic institutions, and professional societies to invest resources to develop, test, and promote best practices in mentorship. One such approach is the well-studied Entering Mentoring, a process-based professional development curriculum (hereafter referred to as research mentor training [RMT] that has been tested via a randomized
David Feldon, Monitoring Editor

Submitted Mar 8, 2018; Revised May 29, 2018 Accepted Jun 27, 2018

CBE Life Sci Educ September 1, 2018 17:ar48 DOI:10.1187/cbe.18-03-0034

Conflict of interest: Kimberly C. Spencer, Christine A. Sorkness, Pamela Asquith, and Christine Pfund are authors of one or more of the curricula in the Entering Mentoring series. No promotion of this particular curricular series should be construed.

*Address correspondence to: Kimberly C. Spencer (kcspencer2@wisc.edu).

() 2018 K. C. Spencer et al. CBE-Life Sciences Education @ 2018 The American Society for Cell Biology. This article is distributed by The American Society for Cell Biology under license from the author(s). It is available to the public under an Attribution-Noncommercial-Share Alike 3.0 Unported Creative Commons License (http://creativecommons.org/licenses/ by-nc-sa/3.0).

"ASCB®" and "The American Society for Cell Biology $\circledR^{\prime \prime}$ are registered trademarks of The American Society for Cell Biology. 


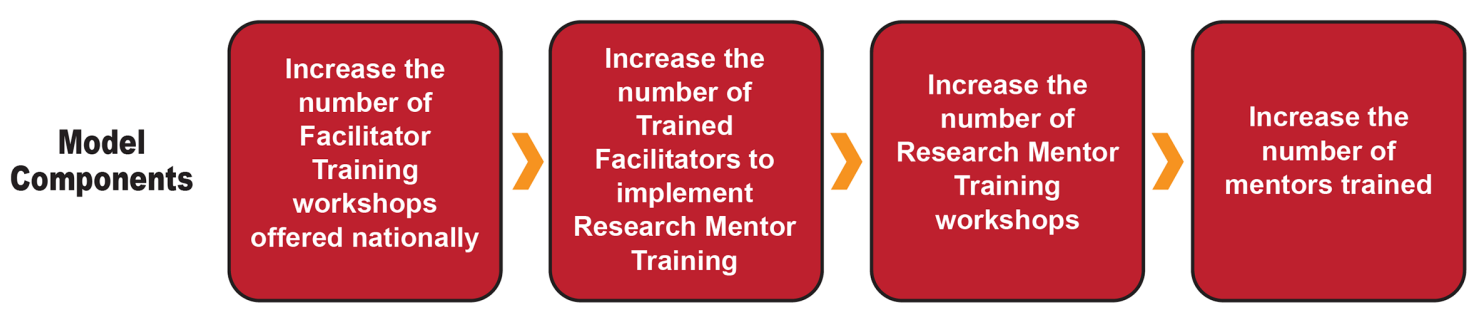

FIGURE 1. Model for building a national capacity for research mentor training.

controlled study [Pfund et al., 2013, 2014a] and adapted for use across many disciplines and career stages [Sorkness et al., 2013; Pfund et al., 2014b]). The Entering Mentoring curriculum covers mentoring domains such as maintaining effective communication, aligning expectations, addressing equity and inclusion, assessing understanding, promoting professional development, and fostering independence. Mentors who participate in Entering Mentoring-based training report skill gains across mentoring domains as well as changes in their mentoring practices. Mentees of participating mentors also report increases in their mentors' skill gains and positive changes in their mentoring practices (Pfund et al., 2014a).

In 2015, the outcomes of initial efforts to build national capacity for this evidence-based approach were published (Pfund et al., 2015). These expansion efforts were based on a train-the-trainer approach of dissemination that is often used by personnel in fields as diverse as education, public health, workforce development, nutrition, primary care, and occupational safety (Clarke and Dede, 2009; Pearce et al., 2012; Yarber et al., 2015; Baldwin et al., 2017) to expand the network of researchers exposed to an intervention and promote its use (Hutchinson and Huberman, 1994; Rabin and Brownson, 2012). As shown in Figure 1, this model for nationally disseminating RMT posits that increasing the number of train-thetrainer workshops (referred to as facilitator training [FT]) will increase the number of facilitators prepared to implement RMT locally, thus increasing the number of mentors experiencing evidence-based RMT.

During the FT workshop, participants build the confidence and skills to facilitate RMT in their local contexts. The workshop was designed using core elements of high-quality trainthe-trainer workshops (Baldwin et al., 2017) such that it gave attendees 1) exposure to Entering Mentoring through experiencing modules and receiving copies of the full curriculum; 2) practice facilitating the curriculum and receiving feedback; 3) opportunity to design an implementation plan to support the organization and delivery of the curriculum in local contexts; and 4) access to resources and a peer network to support implementation over time.

This paper describes the infrastructure developed to sustain and support the continued expansion of the national network of facilitators trained to offer RMT using the model shown in Figure 1. Empirical research examining this FT model has focused upon its effectiveness for increasing participant knowledge, skills, and confidence to implement targeted interventions (Pfund et al., 2015). However, follow-through implementation in local contexts is often inconsistent (Ray et al., 2012), even among the most effective interventions. Identified barriers to implementation include lack of time, resources, rewards, expertise, and confidence to implement (Hutchinson and Huberman, 1994; Henderson and Dancy, 2007; Henderson et al., 2011; American Association for the Advancement of Science, 2011; D'Avanzo, 2013).

The infrastructure approaches described here incorporate strategies to overcome barriers to implementation and support a national propagation of RMT. Approaches include 1) developing a Master Facilitator Initiative to train experts to deliver FT, 2) adapting RMT curricula for multiple audiences and career stages, 3) providing implementation resources to address implementation barriers, and 4) developing a standardized evaluation tool to evaluate RMT. Each infrastructure approach is described and data are shared to show national impact and contribution to the expansion of RMT nationwide. These approaches reflect dissemination and implementation factors known to promote utilization and high-quality implementation.

\section{METHODS}

Data were collected to assess the efficacy of the infrastructure approaches using a variety of methods, including online registration and applications, posttraining evaluation and implementation surveys, Google Analytics, and internal and online tracking databases. Data types are described below, and the specific infrastructure approach the data were used to assess is noted. The infrastructure approaches themselves are described in detail in the next section.

\section{Master Facilitators}

Experts who deliver FT are referred to as "master facilitators" (approach 1). Master facilitators are required to submit an online application, which captures information on demographics, professional background, facilitation experience, and evidence of facilitation skills/effectiveness (Supplemental Material).

\section{FT Application}

Individuals interested in attending FT workshops are required to complete an application survey in which they share information on their demographics, professional backgrounds, facilitation experience, and plans to implement RMT (approach 3) (Supplemental Material).

\section{FT Evaluation}

FT attendees are required to complete an evaluation survey after participating in the training. Surveys are administered in both paper format and online through University of Wisconsin-Madison (UW-Madison) Qualtrics Software. Data reported in this article were collected from 281 FT participants (73\% response rate). Attendees rated the value of each individual component of the FT workshop on a Likert-like 
scale, with $1=$ not at all valuable, $2=$ somewhat valuable, $3=$ valuable, and $4=$ very valuable. Several FT evaluation surveys also used a five-point scale with $5=$ extremely valuable. For reporting in this article, the 4 and 5 categories were combined (approach 1). Attendees also retrospectively rated their confidence in facilitation skills, comparing their confidence before and after the FT workshop on a seven-point Likert scale, with $1=$ not at all confident, $4=$ moderately confident, and $7=$ extremely confident. Differences in ratings before and after FT were determined by Wilcoxon signed-rank test (approach 3). Evaluation surveys also contained open-ended questions regarding attendees' intent to implement RMT, what additional resources might be needed for RMT implementation, what improvements could be made to the FT workshop, and any peer connections made or support used during the workshop. These open-ended responses were qualitatively analyzed using a thematic analysis (approach 3; Boyatzis, 1998; Braun and Clarke, 2006).

\section{Google Analytics and Online Databases}

Website usage data were collected through Google Analytics for three websites that hosted curricula and implementation resources (approach 2). Website curricula downloads are tracked by requiring users to create profiles to access and download RMT curricula. This information is stored on the website portal and downloaded into a spreadsheet. Data were reported on www.researchmentortraining.org, which was active from 2009 to 2016; https://ictr.wisc.edu/mentoring, which was active from 2013 to 2016; and the currently active website, www.cimerproject.org, from April 2016 to January 2018.

\section{Internal Tracking Databases}

Internal tracking databases are used to record national trainings facilitated by master facilitators and local trainings led by trained facilitators. Information collected includes names of facilitators, dates of training, location of training, curricula used for the training, competencies covered in the training, and number and career stage of workshop participants (approach 1). Tracking databases are also used to record whether facilitators use internal evaluation surveys hosted through UW-Madison Qualtrics to evaluate and assess the effectiveness of their training(s) (approach 4).

\section{Implementation Survey}

Implementation surveys are electronically administered to FT participants annually to collect information on their implementation practices and any supports or barriers they have experienced since attending FT. Participants also retrospectively rate their confidence in implementing, thinking back to before they attended the FT workshop and "now" after implementing RMT ( 1 = not at all confident, $4=$ moderately confident, $7=$ extremely confident) and whether or not they felt they were prepared to facilitate after attending the training $(1=$ a little prepared, $2=$ a moderate amount, $3=$ a lot prepared, $4=$ a great deal prepared; approach 3). Participants also rate the helpfulness of the FT workshop in preparing them to implement training locally ( 1 = extremely unhelpful, 2 = unhelpful, $3=$ neither, $4=$ helpful, 5 = extremely helpful; approach 3). Additionally, participants are asked to report the number of training workshops they facilitated each year since attending the FT workshop and to rate the overall quality of their local implementations on a Likert scale with $1=$ very low, $2=$ low, $3=$ average, $4=$ high, $5=$ very high (see Impact of Sustainability Infrastructure). Data reported in this article were collected from 144 of 477 FT participants (30\% response rate) who completed the 2016 implementation survey.

\section{INFRASTRUCTURE APPROACHES AND SUPPORTING DATA \\ Approach 1: Develop a Master Facilitator Initiative to Increase the Number of Trained Facilitators}

Whether or not an intervention has enough human capital to scale efforts is an important factor in determining whether it will be sustainable (Barker et al., 2016). For the Entering Mentoringbased RMT curricula to be nationally disseminated (Handelsman et al., 2005), a group of experts trained to deliver FT workshops were needed to increase the number of prepared facilitators to implement RMT (Figure 1; Ray et al., 2012). Until 2015, a small team of five UW-Madison experts led the majority of the FT workshops (Pfund et al., 2015). A Master Facilitator Initiative was developed as part of the National Research Mentoring Network (NRMN) to increase the number of experts across disciplines and institutions (McDaniels et al., 2018; www.nrmnet .net). The primary goal of this initiative was to develop a group of experts who could lead mentorship trainings across the country on behalf of NRMN. However, a subset of this group was also trained to lead FT workshops, which are multiday, multifaceted events requiring substantial preparation (Figure 2).

To become a master facilitator, individuals must submit an application, which is reviewed internally. Requirements for master facilitators include participation in both RMT and FT, evidence of effective facilitation of RMT, commitment to equity and inclusion, and the ability to nurture self-reflection and learning in support of more equitable and efficacious mentoring relationships. Evidence of effective facilitation is collected from their training participants through a centralized evaluation (approach 4). To support the master facilitators, a professional development program was designed to encourage the continued growth of their expertise and ensure quality of facilitation. Key components of this professional development program include monthly newsletters, webinars, online learning communities, and annual in-person meetings.

Since the Master Facilitator Initiative was launched in 2015, 38 master facilitators have been designated, and the number of experts prepared to lead or co-lead FT workshops increased from 5 to 22. Enlarging the overall group of experts and increasing the number of experts capable of delivering FT enabled more FT workshops to be held nationally, thus increasing the number of facilitators trained to implement RMT. Overall, these efforts have resulted in 24 FT workshops in which 597 facilitators have been trained (Table 1). These FT workshop were held in a variety of settings, including public universities (UW-Madison, University of Cincinnati, Portland State University, University of Maryland, University of Minnesota, University of Puerto Rico, University of San Diego, Georgia State University), private institutions (Vanderbilt University, Boston University, Boston College), medical schools (Albert Einstein College of Medicine, Rutgers New Jersey Medical School, Medical College of Wisconsin), the Big Ten Academic Alliance, the annual conference of the Society for Chicanos/Hispanics and Native Americans in 


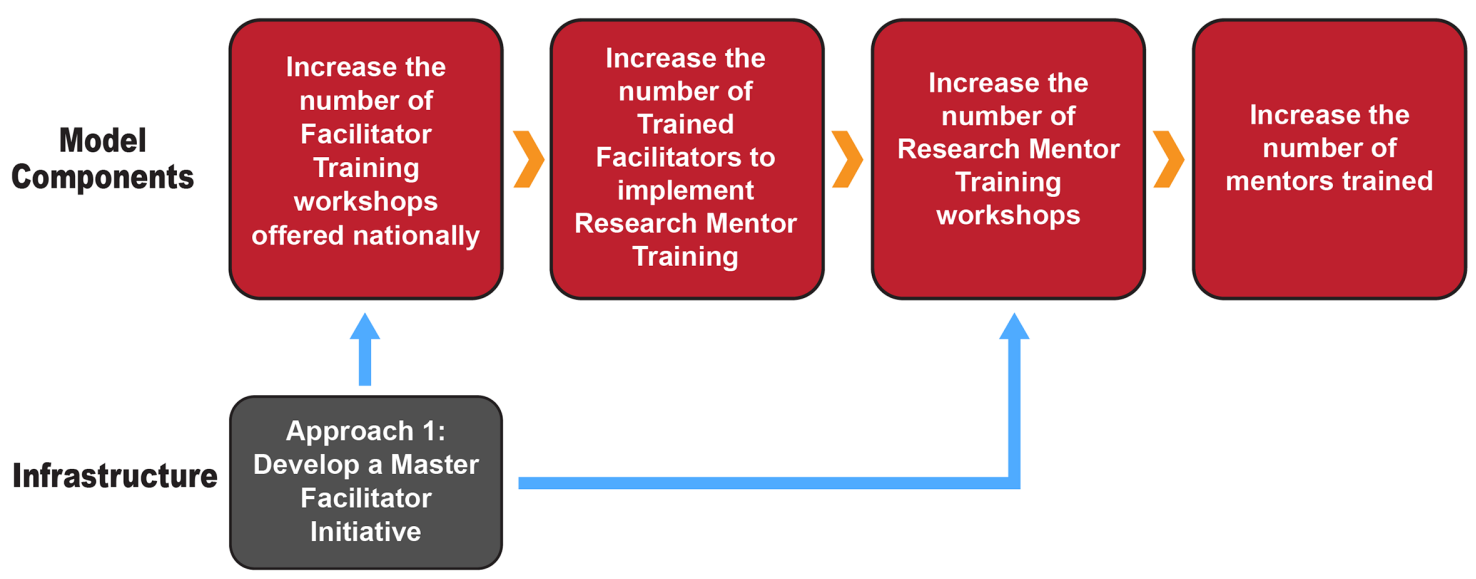

Master Facilitators are experts who lead both Facilitator Training and Research Mentor Training workshops.

FIGURE 2. Using a Master Facilitator Initiative to build a national capacity for research mentor training.

Science (SACNAS), and the Annual Biomedical Research Conference for Minority Students (ABRCMS).

FT workshop attendees represent a wide range of career stages as reported on the FT application and evaluation surveys. FT attendees were $24.2 \%(n=82)$ full professors, $15.6 \%$ $(n=53)$ associate professors, $11.8 \%(n=40)$ assistant professors, $10.9 \%(n=37)$ training program directors, $9.1 \%(n=31)$ deans or administrators, and $15.9 \%(n=54)$ other (i.e., scientists, postdoctoral fellows, instructors). FT attendees were $66 \%$ $(n=213)$ female and $33 \%(n=106)$ male, with $3(0.9 \%)$ preferring not to report. FT attendees mostly self-identified as white $(n=189,63 \%)$ and non-Hispanic $(n=203,70.5 \%)$, with 40 (13.3\%) identifying as Black or African American, 4 (1.3\%) as American Indian or Alaskan Native, 29 (9.7\%) as Asian, 6 $(2.0 \%)$ as Native Hawaiian or Pacific Islander, $24(9.4 \%)$ as Puerto Rican, 7 (2.7\%) as Mexican or Chicanx, $3(1.2 \%)$ as Cuban, 16 (6.3\%) as other Hispanic, and 14 (4.7\%) as unknown or not reported. Additionally, the FT attendees represent 152 academic institutions.

Data collected from the 2016 implementation survey indicate that FT participants are implementing RMT. Of the 144 survey respondents, $109(76 \%)$ indicated that they facilitated RMT since attending the FT workshop, 21 indicated they did not implement but have plans to do so, and 14 reported they had not implemented training. The 109 participants who indicated they implemented training reported facilitating 410 RMT workshops (Table 1).

\section{Approach 2: Adapt RMT Curricula for Multiple Audiences and Career Stages and Increase Accessibility}

One of the key factors in promoting sustained dissemination is the extent to which material is adaptable, accessible, and available (Hutchinson and Huberman, 1994; Rabin and Brownson, 2012). Such resources reduce the time that frontline implementers, in this case the facilitators, need to prepare for implementation in their local settings (Froyd, 2007). Entering Mentoring was originally developed to improve the effectiveness of graduate student and postdoctoral mentors working with undergraduate researchers (Handelsman et al., 2005). Over time, requests increased for curricular adaptations that retained the efficacy of the original curriculum, yet were relevant for multiple audiences and career stages. In response to these requests, new RMT curricula and modules were developed (Table 2). Through these efforts, Entering Mentoring was adapted for research mentors, graduate students to senior faculty, who work with trainees across various career stages and disciplines, across STEM (Pfund et al., 2014b). From 2010 to 2012, the curriculum was adapted for research mentors of junior faculty trainees engaged in clinical and translational, biomedical, clinical and behavioral, and community-engaged research (Pfund et al., 2012, 2014c; Sorkness et al., 2013; Asquith et al., 2014; House et al., 2014). In 2016, the curriculum was further adapted for research mentors of trainees engaged in the social sciences (Robert and Asquith, 2017).

TABLE 1. Building capacity for research mentor training ${ }^{a}$

\begin{tabular}{lccccc}
\hline Year & $\begin{array}{c}\text { Number of master } \\
\text { facilitators }\end{array}$ & $\begin{array}{c}\text { Number of master } \\
\text { facilitators able to } \\
\text { deliver FT }\end{array}$ & Number of FTs & $\begin{array}{c}\text { Number of trained } \\
\text { facilitators }\end{array}$ & $\begin{array}{c}\text { Number of RMT } \\
\text { workshops led by } \\
\text { trained facilitators }\end{array}$ \\
\hline $2010-2011$ & 5 & 5 & $1^{\mathrm{b}}$ & $38^{\mathrm{b}}$ & $33^{\mathrm{c}}$ \\
$2012-2013$ & 9 & 9 & $9^{\mathrm{b}}$ & $165^{\mathrm{b}}$ & $60^{\mathrm{c}}$ \\
$2014-2017$ & 38 & 13 & 14 & 394 & $317^{\mathrm{c}}$ \\
Total & 38 & 22 & 24 & 597 & $410^{\mathrm{c}}$ \\
\hline
\end{tabular}

aData source: internal tracking spreadsheets.

bData reported in Pfund et al. (2015).

'Data from 2016 implementation survey (144 respondents). 
TABLE 2. RMT curricula and module expansions

\begin{tabular}{ll}
\hline Complete curricula $^{a}$ & \multicolumn{1}{c}{ Career stage } \\
\hline Entering Mentoring (1st ed.) & Mentors of undergraduate and graduate students \\
Entering Mentoring (2nd ed.) & Mentors of undergraduate and graduate students \\
Mentor Training for Clinical and Translational Researchers & Mentors of junior faculty and postdoctoral fellows \\
Mentor Training for Biomedical Researchers & Mentors of junior faculty and postdoctoral fellows \\
$\begin{array}{l}\text { Mentor Training for Clinical and Behavioral Researchers } \\
\text { Mentor Training for Community-Engaged Researchers }\end{array}$ & Mentors of junior faculty, postdoctoral fellows, and graduate students \\
Mentor Training for Social Science Researchers & Mentors of junior faculty and postdoctoral fellows \\
\hline Modules & Mentors of junior faculty and postdoctoral fellows \\
\hline "Promoting Mentee Research Self-Efficacy" & \\
"Culturally Aware Mentoring" & Mentors of all trainee career stages \\
"Enhancing Work-Life integration" & Mentors of all trainee career stages \\
"Asynchronous Online Training: Optimizing the Practice of Mentoring " & Mentors of postdoctoral fellows and faculty \\
\hline
\end{tabular}

${ }^{a}$ Complete curricula and modules are available through www.cimerproject.org via download or by request.

New modules on focused topics were also developed, including: "Promoting Mentee Research Self-Efficacy" (Byars-Winston et al., 2017; Butz et al., 2018), "Enhancing Work-Life Integration" (Durbin and Meagher, 2015), and "Culturally Aware Mentoring" (Byars-Winston et al., 2018). These new curricula and modules have been beta-tested, and assessment scales have been developed to assess training outcomes. RMT curricula and modules are often adapted and expanded for new audiences with support from cross-institutional partnerships and external funding.

Although the Entering Mentoring curriculum was adapted for multiple audiences and career stages, it also had to be adaptable for use in multiple formats. For example, the original Entering Mentoring curriculum was initially used in an 8-week summer seminar for graduate students and was not easily adjusted for other types of implementations (Handelsman et al., 2005). Curricula in this series were not only revised for use across multiple audiences, but also to allow for shorter, modular implementation to increase adaptability. This adjustment allowed facilitators to implement different parts of the curriculum for use in their local contexts, customizing the content to the needs of the populations they serve and accommodating different training durations. Revisions included new, user-friendly facilitator guides with step-by-step implementation instructions, learning objectives, additional activities, and suggested time allotments to provide more clarity for implementation and strategies for adaptation.

Increased accessibility and availability of the curricula and resources were made possible through an open-access website developed to house Entering Mentoring complete curricula and modules for those mentoring junior faculty, postdoctoral fellows, graduate students, and undergraduate students (www .cimerproject.org). On the website, trained facilitators (and other interested parties) can download full curricula and complete modules or create customized curricula by "mixing and matching" modules and activities depending upon the content of interest, career stages, and research background of their local audiences. The website also contains planning and recruitment information, facilitator guides, evaluation tools, and other resources to promote easy implementation. New curricula and modules are made available on the website as they are developed, allowing facilitators access to new content.
Website usage data suggest that trained facilitators, as well as others, are accessing these resources to support their implementation efforts. To date, three websites have housed Entering Mentoring-based curricula. The first website, www .researchmentortraining.org (now inactive), allowed users to download complete and customized curricula. More than 4000 documents were downloaded from this site. The second website, https://ictr.wisc.edu/mentoring, which has since been reworked and no longer hosts curricular materials, allowed 397 unique individuals to download complete or customized curricula. The CIMER website (www.cimerproject.org), launched in 2017, hosts all of the full and customizable curricula.

\section{Approach 3: Provide Implementation Resources to Address Barriers to Implementing RMT}

Efforts to build a sustainable infrastructure to expand RMT should account for characteristics of institutions (local contexts for implementation), individuals (participants in FT), and the curriculum itself, from which barriers and enablers to implementation emerge (Ray et al., 2012; Nilsen, 2015). The existence of these factors and associated barriers and enablers were considered when creating and disseminating resources for implementation.

As previously reported, despite increases in skills and confidence, FT workshop participants reported perceived barriers to implementing RMT in their local contexts (Pfund et al., 2015). Subsequent qualitative data collection with thematic analysis (Boyatzis, 1998; Braun and Clarke, 2006) of recent FT workshop participants' $(N=123)$ responses to the FT evaluation survey question "Please describe any additional resources you would need to effectively implement research mentor training?" indicates that institutional support (22\%) and trainer support (21\%) continue to be important for successful implementation. While $15 \%$ of respondents indicated they were ready to implement and did not need any additional support or resources, the majority of participants described needing assistance for planning and organization, supported institutional time for implementing training, consultation with experienced facilitators, and access to evaluation tools. Other less common themes included unknown or to be determined support (15\%), access to training materials such as via website $(15 \%)$, lack of professional time $(5 \%)$, further participation in FT and/or RMT (5\%), and other (2\%). 
TABLE 3. Implementation planning worksheet example questions

\begin{tabular}{l}
\hline Recruitment \\
\hline - Who is your target audience for research mentor training on your campus? \\
\hline Important stakeholders \\
\hline - Who do you need to convince that mentor training is worth the time and investment? \\
- What information could be used to convince those stakeholders? \\
\hline Training details and design \\
\hline - Which training do you plan to implement (career stage, disciplinary context)? \\
$\quad$ In what time frame and format will your training(s) be delivered (e.g., academic year, summer, multiple 1-2 hour sessions or single \\
$\quad$ Will your training be integrated or serve an existing program (e.g., career development series for junior faculty, graduate or fellows training \\
\hline Challenges to implementation \\
\hline$\quad$ What barriers to implementation of research mentor training might you face at your institution? \\
- What strategies might be taken to overcome any barriers or challenges to implementation?
\end{tabular}

In an effort to increase facilitation preparedness (Cohen and Ball, 2007) and the likelihood that facilitators would implement RMT, FT workshops were restructured in 2015 to focus more attention on addressing barriers to successful implementation. As part of the restructure, a new session on strategic planning was added so participants could learn about implementation resources and develop customized implementation plans. During this session, participants are provided with an implementation planning worksheet that includes a series of questions to consider regarding recruitment, training design and audience, resources for implementation, anticipated challenges, and "first next steps" upon returning to their home institutions (Table 3 ).

Barriers to implementation were also addressed through a targeted recruitment strategy that was enforced to ensure that FT participants have peer implementation support during and after the FT workshop. For example, participants from the same institution are encouraged to attend the FT together and requests to host FT workshops with a regional impact are given high priority. Priority registration is also given to applicants who indicate specific plans to implement RMT within the next year.

To ensure quality of FT workshops led by master facilitators, data are collected in the FT evaluation surveys. As in workshop satisfaction data previously reported (Pfund et al., 2015), the majority of FT participants report components of the FT workshop as valuable. The three new FT components integrated since the 2015 article (Pfund et al., 2015) are also favorably rated (Table 4).

During the FT workshop, time is set aside for networking, and participants are encouraged to work with attendees from the same or similar institutions during the strategic planning session to develop implementation plans. This approach to cohort building enables facilitators from similar institutions or disciplines to collaborate with one another and create capacity to connect after they return to their institutions (Froyd, 2007). Several open-ended questions were added in the FT evaluation survey to assess whether adding strategic planning components and opportunities for networking and peer support were helpful. In response to the question "If applicable, describe the connections you made during this workshop (e.g., Did you make connections with multiple attendees? Do you anticipate maintaining connections with attendees outside the workshop? Was the mix of attendees valuable?)," 114 responses were analyzed to discern the value and nature of connections made during the FT workshop. Overall, the data indicate that FT workshop design and activities promoted networking and informed participants' implementation plans. Overwhelmingly, 98\% of the survey respondents reported that they made connections with multiple attendees at the workshop and, of those, 100\% indicated those interactions were valuable. Of the 112 participants who indicated that valued connections were made, $73 \%$ explicitly mentioned the merits of institutional connections: either meeting with colleagues at their own institution, other institutions, or both.

Additional data were collected to assess whether efforts to address barriers to implementation and increase facilitator preparedness were effective, including data collected in the FT evaluation survey and 2016 implementation survey. In the FT evaluation survey, participants retrospectively reported increased

TABLE 4. Satisfaction with new or adapted FT workshop components ${ }^{\mathrm{a}}$

\begin{tabular}{|c|c|c|c|}
\hline Implementation and resources components & $n$ & Average rating $^{\mathrm{b}}$ & SD \\
\hline Data/evidence for recruitment & 269 & 3.41 & 0.765 \\
\hline Website overview & 261 & 3.34 & 0.792 \\
\hline Evaluation measures of research mentor training & 247 & 3.518 & 0.7147 \\
\hline
\end{tabular}

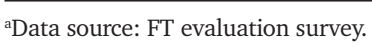

bWorkshop components were rated on a Likert scale: $1=$ not at all valuable, $2=$ somewhat valuable, $3=$ valuable, $4=$ very valuable. 
TABLE 5. Self-reported confidence gains before and after attending $\mathrm{FT}^{\mathrm{a}}$

\begin{tabular}{|c|c|c|c|c|c|c|c|}
\hline \multirow[b]{2}{*}{ Learning objective } & \multicolumn{3}{|c|}{ Before } & \multicolumn{3}{|c|}{ After } & \multirow[b]{2}{*}{ Difference } \\
\hline & $n$ & Mean & SD & $n$ & Mean & SD & \\
\hline To use the available RMT curricula and supporting resources & 276 & 3.06 & 1.440 & 279 & 4.99 & 1.281 & $p<0.000$ \\
\hline To describe evidence to support the effectiveness of RMT & 278 & 2.96 & 1.542 & 279 & 4.67 & 1.414 & $p<0.000$ \\
\hline To facilitate RMT using the process-based approach & 276 & 3.04 & 1.496 & 277 & 4.94 & 1.327 & $p<0.000$ \\
\hline To recruit mentors to participate in training & 274 & 3.22 & 1.486 & 274 & 4.52 & 1.415 & $p<0.000$ \\
\hline To implement RMT at your home institution & 275 & 3.17 & 1.599 & 277 & 4.95 & 1.425 & $p<0.000$ \\
\hline To use metrics and tools to assess the effectiveness and impact of RMT & 277 & 2.92 & 1.552 & 277 & 4.47 & 1.488 & $p<0.000$ \\
\hline To understand the implementation process & 161 & 3.41 & 1.723 & 161 & 5.58 & 1.273 & $p<0.000$ \\
\hline
\end{tabular}

aData source: FT evaluation survey.

bifferences in ratings before and after FT were determined by Wilcoxon signed-rank test. Confidence was rated on a seven-point Likert scale: 1 = not at all confident, $4=$ moderately confident, 7 = extremely confident.

confidence in aspects related to implementation (Table 5), which agrees with previously reported data (Allen and Nimon, 2007; Pfund et al., 2015). In the implementation survey, participants reported confidence gains comparing how they felt before attending the FT workshop and after they implemented RMT (Table 6).

In the implementation survey, participants also retrospectively rated their preparedness to implement RMT, reflecting back to how they felt after attending the FT workshop. Of the 98 survey respondents, 29 (30\%) reported feeling "A great deal prepared," 30 (31\%) "A lot prepared," 33 (34\%) "A moderate amount," and 6 (6\%) "A little prepared." Participants also answered how helpful the FT workshop was in helping them prepare for implementation. Of the 94 survey respondents, 91 (97\%) reported the FT workshop was either extremely helpful or helpful.

\section{Approach 4: Develop a Standardized Approach to Evaluate the Quality of RMT Implementations Nationally}

Critical components in ensuring the quality of any implementation and dissemination effort are standardized evaluation and tracking tools (Hutchinson and Huberman, 1994; Barker et al., 2016) and processes for using these data for the continuous improvement of the intervention effort as a whole (Baldwin et al., 2017).

To increase capacity for ongoing assessment of intervention efficacy, both in terms of the quality of the curricula and facilitation efforts, an assessment tool was developed to test skill gains across mentoring domains (Fleming et al., 2013) and made available to facilitators for evaluating RMT workshops at their home institutions. This Mentoring Competency Assessment was first used with facilitators in 2010 and then became freely available on an online Web portal after it was validated (Fleming et al., 2013).
In 2016, a research and evaluation team was developed to standardize and systematize data collection and evaluation metrics for workshops led by master facilitators and trained facilitators using Entering Mentoring-based curricula. The main goal of this effort is to collect nationwide data to inform future implementation of and research on RMT. To incentivize use of assessment tools, the team provides customization of core assessment surveys; evaluation surveys include standardized questions so that aggregate data can be reported and compared but also allow for inclusion of site- or training-specific questions to meet the needs of the user. Assessment surveys are available for all types of implementations, no matter the length or venue.

The centralized evaluation system allows for data collection at multiple points in the dissemination process and for large-scale comparison of all FT workshops as well as the subsequent RMT. For example, FT participants are surveyed immediately after training and annually to track implementation efforts. As facilitators implement RMT locally, the research and evaluation team provides evaluation services for the RMT. Core data include satisfaction with the training, perceived skill gains and perceived quality of mentoring gains, intent to make changes in their mentoring relationships, mentoring background, and demographics (Supplemental Material). As of Summer 2017, this centralized evaluation system has been used to collect data from more than 200 events and 2000 participants (Table 7).

\section{IMPACT OF SUSTAINABILITY INFRASTRUCTURE}

To increase the national dissemination of evidence-based RMT for mentors across career stages and disciplines, a multicomponent infrastructure was developed and continues to be refined to sustain and support the continued expansion of a national network of trained facilitators capable of offering RMT. Data in

TABLE 6. Self-reported confidence gains in ability to implement RMT

\begin{tabular}{lcccc}
\hline Item & $\boldsymbol{n}$ & Mean & SD & Difference $^{\mathrm{b}}$ \\
\hline Confidence before attending the FT & 96 & 3.29 & 1.450 & $p<0.000$ \\
Confidence now after implementing & 95 & 5.93 & 1.024 & $p$ \\
\hline
\end{tabular}

aData source: 2016 implementation survey.

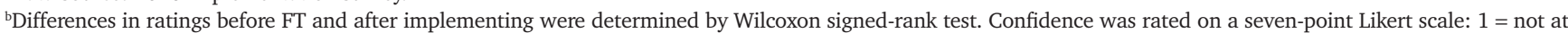
all confident, $4=$ moderately confident, $7=$ extremely confident. 
TABLE 7. Standardized evaluation of training ${ }^{a}$

\begin{tabular}{lcccccc}
\hline & \multicolumn{2}{c}{ Master facilitators } & & \multicolumn{2}{c}{ Trained facilitators } \\
\cline { 2 - 3 } Type of training & 23 & $\begin{array}{c}\text { Number of events using } \\
\text { centralized evaluation }\end{array}$ & $\begin{array}{c}\text { Number of participant } \\
\text { surveys }\end{array}$ & $\begin{array}{c}\text { Number of events using } \\
\text { centralized evaluation }\end{array}$ & $\begin{array}{c}\text { Number of participant } \\
\text { surveys }\end{array}$ \\
\hline FT & 77 & 293 & - & - & 561 \\
RMT & 17 & 879 & 175 & 15 & 150 \\
Research mentee training & 117 & 1347 & & 78 & 711 \\
Total & & & & & \\
\hline
\end{tabular}

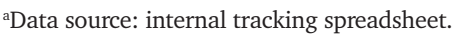

this article provide evidence for the effectiveness of the FT model and infrastructure approaches to increase the number of trained facilitators implementing RMT at their respective institutions (Figure 3).

Through the centralized evaluation and internal tracking systems, implementation and evaluation data are being collected from master facilitators, trained facilitators, and RMT participants across the nation. Using the implementation survey, trained facilitators report the number of RMT workshops they have implemented since attending the FT workshop (Figure 3). Trained facilitators were not asked to provide the number of training participants in their workshops in the implementation survey; however, these data are captured through internal tracking databases for trained facilitators using centralized evaluation. These databases indicate that, on average, 10 participants attend RMT workshops led by trained facilitators. Given that trained facilitators reported implementing 410 RMT workshops, it is reasonable to assume that more than 4000 research mentors have been trained.

Although not included in this article, initial analyses from RMT participants indicate high workshop satisfaction and increases in mentoring skills gains, suggesting that the vast majority of trained facilitators are effective. Further, self-reported data in the implementation survey indicate that the majority of trained facilitators rate their implementation quality as very high or high with 16 (17\%) reporting the quality as very high, 49 (51\%) as high, $29(30 \%)$ as average, $2(2 \%)$ as low or very low.

\section{DISCUSSION}

Over the past several decades, federal agencies have invested in projects that support the dissemination of evidence-based practices aimed at diversifying the students, faculty, and other researchers in STEM fields (National Institute of General Medical Sciences, 2011). Of particular concern in recent years has been the realization that the biomedical research workforce in the United States does not mirror the nation's demographic diversity (Valantine and Collins, 2015; Pfund et al., 2016). In response, the National Institutes of Health (NIH) announced the awardees of the $\$ 250$ million NIH Diversity Consortium, a collaborative designed to develop and test interventions that engage trainees, including those from historically underserved backgrounds, and prepare them to thrive in NIH-funded careers (Valantine and Collins, 2015; Pfund et al., 2016). One of the consortium members, the NRMN, aims to increase the diversity of scientists in NIHfunded research specifically through evidence-based mentorship and professional development programming (www.NRMNet .net; https://commonfund.nih.gov/diversity/Initiatives; Guerrero et al., 2017; Jones et al., 2017; Sorkness et al., 2017).

In 2014, UW-Madison received federal funding to lead the Mentorship Training Core of NRMN and serve as a national hub to deliver evidence-based training programs designed to help mentors and mentees engage in productive, culturally responsive mentoring relationships. Several interventions have been developed and tested to address the need for equitable access to quality mentoring. A team from UW-Madison developed one

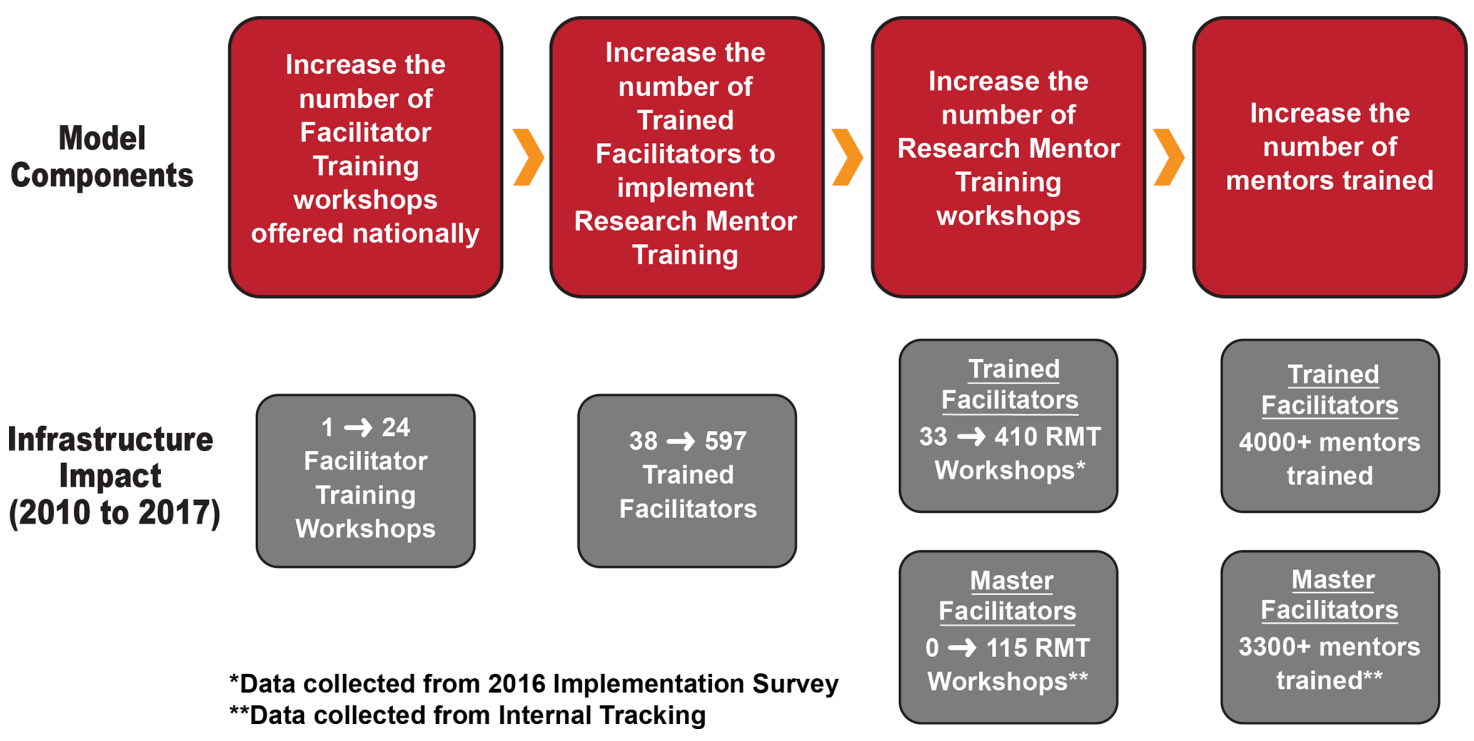

FIGURE 3. Model components and impact of infrastructure approaches for national dissemination of research mentor training. 
such intervention-the Entering Mentoring RMT curriculum described in this article. Although this intervention and others have been well studied, it is critical that these approaches are also effectively disseminated. A previous publication (Pfund et al., 2015) described the first step in supporting dissemination of the Entering Mentoring curriculum, which included development and testing of an FT workshop aimed at increasing the number of individuals able to effectively deliver Entering Mentoring to a larger audience.

This article builds upon the previously published work and describes the infrastructure that was subsequently developed and its impact, with support of NRMN funds, to promote both a sustainable expansion of FT workshops and the success of FT workshop participants as they implement the Entering Mentoring curricula in their local contexts. This approach was guided by the literature on dissemination, implementation, and scale-up (Hutchinson and Huberman, 1994; Cohen and Ball, 2007; Rabin and Brownson, 2012; Barker et al., 2016), with a focus on increasing the accessibility and adaptability of the curricula, developing resources targeted at overcoming barriers to implementation, providing opportunities for connection among implementers, and monitoring implementation quality across local contexts. The four infrastructure approaches described in this paper include:

1. An expansion initiative to increase the number of expert facilitators able to deliver FT workshops nationwide

2. Accessible RMT curricula adapted for multiple audiences and career stages

3. Implementation resources to support facilitators and help them overcome implementation barriers

4. Standardized evaluation of training

Strong evidence supporting each of these infrastructure approaches and their national impact is reported for 597 trained facilitators, $30 \%$ of whom have reported on their implementation efforts. These facilitators self-report facilitating RMT in their local contexts for more than 4000 graduate student, junior faculty, and senior faculty mentors. There is evidence that this number is underreported by trained facilitators, as we know some have implemented through use of evaluation and did not complete the implementation survey.

Evidence also exists that diffusion, a more passive, unplanned dissemination process is taking place (Rogers, 2003; Rabin and Brownson, 2012). For example, website curricula downloads and evaluation requests indicate that individuals who have not participated in FT are implementing Entering Mentoring-based RMT. Some of these individuals have participated in RMT themselves, while others have discovered materials through national outreach efforts supporting the accessibility and usability of the Entering Mentoring curricula. Given the low implementation survey response rate and limited knowledge on implementation efforts of individuals who have not attended an FT workshop, other factors should be explored to further examine the impact of these approaches on increasing facilitator implementation.

Although this evidence supports the dissemination model, more data must be collected to understand why some FT attendees are not implementing and what infrastructure needs to be developed to address implementation barriers. Currently, data on implementation barriers and supports are being collected annually, including information on factors that may have impacted initial decisions/ability to implement training, ways institutions have supported efforts to implement training, and any institutional/organizational barriers encountered during the planning process. Initial analyses show commonalities among FT participants regarding individual and institutional barriers, such as lack of time and lack of administrative support, as well as the need for planning and organization assistance, supported institutional time for implementing training, consultation with experienced facilitators, and access to standardized, readily available evaluation tools. Future analyses can further examine these barriers and supports to understand what differences exist, if any, among different subgroups of facilitators identified by race/ethnicity, career stage, gender, and other variables.

It is additionally critical to address the facilitators who are using Entering Mentoring-based curricula but have not attended an FT workshop. As mentioned earlier, website tracking shows that individuals who have not attended FT or used centralized evaluation are downloading RMT curricula. Additional recruitment and outreach efforts need to be implemented so that these individuals can benefit from the infrastructure and resources developed.

Several efforts are underway to provide additional support to increase the number of facilitators prepared and motivated to implement training. In 2017, an NRMN Facilitator Certification Program was implemented to recognize facilitators who have demonstrated individual commitment to the local dissemination of RMT. Eligible facilitators receive a letter of recognition and exclusive access to curated resources. This recognition provides facilitators institutional leverage for implementing training efforts at their institutions or organizations. Other resources for trained facilitators, including online communities and opportunities for additional professional development and networking, are also in development.

Additional resources to support implementation across a range of contexts that are aligned with the needs of programs and institutions are essential for continued growth and scale-up, including resources for both RMT and research mentee training. New RMT curricula and modules are continuously in development and made available to facilitators on www.cimerproject .org. In addition to new material for research mentors, development of research mentee training curricula is also needed to empower trainees to get the most out of their research experiences. Entering Research, a research mentee training curriculum designed for undergraduate students in STEM fields (Balster et al., 2010; Branchaw et al., 2010), began revision in 2016 with support from NRMN. The updated curriculum, Entering Research, Version 2, is designed for use with both undergraduate and graduate students with varying levels of research experience. The new version includes revised and new activities and is organized thematically to allow for modular implementation. Once revisions are complete, the curriculum will be available via the website (www.cimerproject.org). Tailored FT workshops are being offered using a train-the-trainer approach to promote national dissemination.

\section{Limitations}

Several possible limitations are acknowledged in this research. First, much of the data on facilitator confidence, preparedness, and implementation efforts are self-reported by FT participants. 
However, data were also collected from the subsequent mentors who participated in training offered by these facilitators. These mentors largely indicated satisfaction with the training, comparable to previously reported data (Pfund et al., 2015). Internal tracking databases and use of standardized evaluation also support the success of this model to increase the number of trained facilitators who implement training. Second, only $30 \%$ of respondents completed the implementation survey, which suggests that those who have not implemented RMT are not completing the survey. This limits data collection on implementation barriers for this group, providing a biased sample. Future data collection should focus on collecting data from those who have not implemented RMT.

\section{Future Directions}

The infrastructure described here is part of an important model for building a sustainable national infrastructure to broadly disseminate evidence-based RMT. However, several challenges still exist and must be addressed. It is important to ensure quality control of RMT as it is broadly implemented among master facilitators and trained facilitators. Centralized data evaluation has allowed for ongoing monitoring and testing of diverse implementations, while contributing to a national data set. Metrics will be designed and validated to assess new curricula and modules as they are developed. A new assessment platform is under development for use on the CIMER website (www .cimerproject.org). This platform will provide facilitators access to curated scales and assessment tools while compiling data for ongoing research on mentoring relationships and training effectiveness. It will also allow for inquiry into training effectiveness across diverse factors such as demographics of facilitators and RMT participants. This streamlined evaluation process will enhance ongoing monitoring of implementation quality and accommodate deeper investigation into the barriers and supports that impact facilitators' decisions to implement training.

Most importantly, efforts are needed to both support and further understand institutionalization of RMT in local contexts, with a particular focus on how to effectively change institutional cultures to explicitly value and reward mentoring. To that end, now that a critical mass of trained facilitators exist within certain institutions, efforts to understand the impact of that critical mass and the role that academic leaders (deans, chairs, directors) play in supporting successful implementation can be investigated. In addition, significant potential exists for richer examination of the strategies new facilitators use upon returning to their home regions and/or institutions to create buy-in and support for RMT implementation. A conceptual lens that shines the light on facilitators as institutional change agents will be explored (Wall, 2009).

As funding mechanisms emerge for the dissemination of interventions that increase effective research mentoring, the infrastructure described here can be leveraged by institutions striving to address the calls for optimization of mentoring relationships for trainees across career stages and disciplines. The model we present can be used for national dissemination of other training interventions.

\section{ACKNOWLEDGMENTS}

Research reported in this publication was supported by the National Institute of General Medical Sciences of the NIH under award number U54GM119023. The content is solely the responsibility of the authors and does not necessarily represent the official views of the NIH. Additional support was provided by the Institute for Clinical and Translational Research supported by the UW-Madison Clinical and Translational Science Award (CTSA) program, the National Center for Advancing Translational Sciences (NCATS), grant 1UL1TR002373.

\section{REFERENCES}

Allen, J. M., \& Nimon, K. (2007). Retrospective pretest: A practical technique for professional development evaluation. Journal of Industrial Teacher Education, 44, 27-42

American Association for the Advancement of Science. (2011). Vision and change in undergraduate biology education: A call to action. Washington, DC

Asquith, P., Shapiro, E., Weber-Main, A. M., Jacobs, E., \& Sorkness, C. A. (2014). Mentor training for clinical and behavioral researchers (W.H. Freeman Entering Mentoring Series). Madison: University of Wisconsin-Madison.

Baldwin, C. D., Chandran, L., \& Gusic, M. E. (2017). Building sustainable professional development programs: Applying strategies from implementation science to translate evidence into practice. Journal of Continuing Education in the Health Professions, 37(2), 106-115. https://doi.org/10.1097/ CEH.0000000000000151

Balster, N. J., Pfund, C., Rediske, R., \& Branchaw, J. L. (2010). Entering Research: A course that creates community and structure for beginning undergraduate researchers in the STEM disciplines. CBE-Life Sciences Education, 9, 108-118.

Barker, P. M., Reid, A., \& Schall, M. W. (2016). A framework for scaling up health interventions: Lessons from large-scale improvement initiatives in Africa. Implementation Science, 11(12). doi 10.1186/s13012-016-0374-x

Beech, B. M., Calles-Escandon, J., Hairston, K. G., Langdon, S. E., LathamSadler, B. A., \& Bell, R. A. (2013). Mentoring programs for underrepresented minority faculty in academic medical centers. Academic Medicine, 88(4), 541-549

Boyatzis, R. E. (1998). Transforming qualitative information: Thematic analysis and code development. Thousand Oaks, CA: Sage.

Branchaw, J., Pfund, C., \& Rediske, R. (2010). Entering research: Workshops for students beginning research in science. New York: Freeman.

Braun, V., \& Clarke, V. (2006). Using thematic analysis in psychology. Qualitative Research in Psychology, 3, 77-101. doi: 10.1191/1478088706qp063oa

Butz, A., Branchaw, J., Pfund, C., Byars-Winston, A., \& Leverett, P. (2018) Promoting STEM trainee research self-efficacy: A mentor training intervention. Understanding Interventions Journal, 9(1).

Byars-Winston, A. M., Branchaw, J., Pfund, C., Leverett, P., \& Newton, J. (2015). Culturally diverse undergraduate researchers' academic out comes and perceptions of their research mentoring relationships. International Journal of Science Education, 37, 2533-2554.

Byars-Winston, A., Leverett, P., Branchaw, J., \& Pfund, C. (2017). Promoting mentee research self-efficacy (Version 5). Madison: University of Wisconsin-Madison.

Byars-Winston, A., Womack, V., Butz, A., McGee, R., Quinn, S., Utzerath, E. $\&$ Thomas, S. (2018). Pilot study of an intervention to increase cultural awareness in research mentoring: Implications for diversifying the scientific workforce. Journal of Clinical and Translational Science, 2(2), 86-94.

Clarke, J., \& Dede, C. (2009). Design for scalability: A case study of the River City curriculum. Journal of Science Education and Technology, 18, 353. https://doi.org/10.1007/s10956-009-9156-4

Cohen, D. K., \& Ball, D. L. (2007). Innovation and the problem of scale. In Schneider, B., \& McDonald, S. (Eds.), Scale-up in education: Ideas in principle (Vol. 1, pp. 19-36). Lanham, MD: Rowman \& Littlefield.

D'Avanzo, C. (2013). Post-Vision and Change: Do we know how to change? CBE-Life Sciences Education, 12(3), 373-382. https://doi.org/10.1187/ cbe.13-01-0010

Dolan, E., \& Johnson, D. (2009). Toward a holistic view of undergraduate research experiences: An exploratory study of impact on graduate/postdoctoral mentors. Journal of Science Education and Technology, 18(6), 487-500. 
Durbin, D., \& Meagher, E. (2015). Enhancing work/life integration. Philadelphia: Children's Hospital of Philadelphia Research Institute and the University of Pennsylvania Perelman School of Medicine.

Fleming, M., House, S., Shewakramani, V., Yu, L., Garbutt, J., McGee, R., ... Rubio, D. (2013). The Mentoring Competency Assessment: Validation of a new instrument to evaluate skills of research mentors. Academic Medicine, 88, 1002-1008.

Froyd, J. E. (2007). Creating a plan to promote broader adaptation of education innovations. In Spalter-Roth, R., Fortenberry, N., \& Lovitts, B. (Eds.), The acceptance of diffusion of innovation: A cross-disciplinary approach to instructional and curricular change in engineering (pp. 163-170). Washington, DC: American Sociological Association.

Ginther, D. K., Schaffer, W. T., Schnell, J., Masimore, B., Liu, F., Haak, L. L., \& Kington, R. (2011). Race, ethnicity, and NIH research awards. Science, 333(6045), 1015-1019.

Guerrero, L., Wallace, S., Harwood, E., Pfund, C., Seeman, H., McCreath, H., \& Christie, C. (2017). Evaluating the National Research Mentoring Network. BioMed Central Proceedings, 11(Suppl 12), 14.

Handelsman, J., Pfund, C., Miller Lauffer, S., \& Pribbenow, C. M. (2005). Entering mentoring: A seminar to train a new generation of scientists. Madison: University of Wisconsin Press.

Helm, E., Prieto, D., Parker, J., \& Russell, M. (2000). Minority medical school faculty. Journal of the National Medical Association, 92(8), 411-414.

Henderson, C., Beach, A., \& Finkelstein, N. (2011). Facilitating change in undergraduate STEM instructional practices: An analytic review of the literature. Journal of Research in Science Teaching, 48, 952-984.

Henderson, C., \& Dancy, M. H. (2007). Barriers to the use of research-based instructional strategies: The influence of both individual and situational characteristics. Physical Review Special Topics-Physics Education Research, 3(2), 020102. https://doi.org/10.1103/PhysRevSTPER 3.020102

House, S., Dearlove, A., Spencer, K., \& Ziegahn, L. (2014). Mentor training for community-engaged researchers (W.H. Freeman Entering Mentoring Series). Madison: University of Wisconsin-Madison.

Hutchinson, J. R., \& Huberman, M. (1994). Knowledge dissemination and use in science and mathematics education: A literature review. Journal of Science Education and Technology, 3(1), 27-47.

Jones, H., McGee, R., Weber-Main, A. M., Buchwald, D., Manson, S., Vishwanatha, J., \& Okuyemi, K. (2017). Enhancing research careers: An example of a US national diversity-focused, grant-writing training and coaching experiment. BioMed Central Proceedings, 11(Suppl 12), 16.

Keyser, D., Lakoski, J. M., Lara-Cinisomo, S., Schultz, D. J., Williams, V. L., Zellers, D. F., \& Pincus, H. A. (2008). Advancing institutional efforts to support research mentorship: A conceptual framework and self-assessment tool. Academic Medicine : Journal of the Association of American Medical Colleges, 83, 217-225.

McDaniels, M., House, S., Pfund, C., Spencer, K., \& Utzerath, E. (2018). Using a Master Facilitator Initiative to build a national network of trainers for research mentor and mentee training. Poster presented at: Understanding Interventions Conference (Baltimore, MD).

Morzinski, J., \& Fisher, J. (2002). A nationwide study of the influence of faculty development programs on colleague relationships. Academic Medicine, 77(5), 402-406.

National Academies of Sciences, Engineering, and Medicine. (2017). Undergraduate research experiences for STEM students: Successes, challenges, and opportunities. Washington, DC: National Academies Press. https://doi.org/10.17226/24622

National Institute of General Medical Sciences. (2011). Investing in the Future: Strategic Plan for Biomedical and Behavioral Research Training (NIH Publication No. 11 7673). Bethesda, MD.

Nilsen, P. (2015). Making sense of implementation theories, models and frameworks. Implementation Science, 10, 53. https://doi.org/10.1186/ s13012-015-0242-0
Pearce, J., Mann, M. K., Jones, C., van Buschbach, S., Olff, M., \& Bisson, J. I. (2012). The most effective way of delivering a train-the-trainers program: A systematic review. Journal of Continuing Education in the Health Professions, 32(3), 215-226.

Pfund, C., Brace, C., Branchaw, J., Handelsman, J., Masters, K., \& Nanney, L. (2014c). Mentor training for biomedical researchers (W.H. Freeman Entering Mentoring Series). Madison: University of Wisconsin-Madison.

Pfund, C., Branchaw, J., \& Handelsman, J. (2014b). Entering mentoring (2nd ed.). New York: W.H. Freeman.

Pfund, C., Byars-Winston, A., Branchaw, J. L., Hurtado, S., \& Eagan, M. K. (2016). Defining attributes and metrics of effective research mentoring relationships. AIDS and Behavior, 20(Suppl 2), 238-248.

Pfund, C., House, S., Asquith, P., Spencer, K., Silet, K., \& Sorkness, C. (2012). Mentor training for clinical and translational researchers (W.H. Freeman Entering Mentoring Series). New York: W.H. Freeman.

Pfund, C., House, S. C., Asquith, P., Fleming, M. F., Buhr, K. A., Burnham, E. L., ... Sorkness, C. A. (2014a). Training mentors of clinical and translational research scholars: A randomized controlled trial. Academic Medicine, $89,774$.

Pfund, C., House, S., Spencer, K., Asquith, P., Carney, P., Masters, K. S., .. Fleming, M. (2013). A research mentor training curriculum for clinical and translational researchers. Clinical and Translational Science, 6, 26-33.

Pfund, C., Spencer, K. C., Asquith, P., House, S. C., Miller, S., \& Sorkness, C. A. (2015). Building national capacity for research mentor training: An evidence-based approach to training the trainers. CBE-Life Sciences Education, 14, ar24.

Rabin, B. A., \& Brownson, R. C. (2012). Developing the terminology for dissemination and implementation research. In Brownson, R. A., Colditz, G. A., \& Proctor, E. K. (Eds.), Dissemination and implementation research in health (pp. 23-54). Oxford, UK: Oxford University Press.

Ray, M. L., Wilson, M. M., Wandersman, A., Meyers, D. C., \& Katz, J. (2012). Using a training-of-trainers approach and proactive technical assistance to bring evidence based programs to scale: An operationalization of the interactive systems framework's support system. American Journal of Community Psychology, 50(3-4), 415-427. https://doi.org/10.1007/ s10464-012-9526-6

Robert, S., \& Asquith, P. (2017). Mentor training for social science researchers (W.H. Freeman Entering Mentoring Series). Madison: University of Wisconsin-Madison.

Rogers, E. M. (2003). Diffusion of innovations. New York: Free Press.

Silet, K. A., Asquith, P., \& Fleming, M. F. (2010). Survey of mentoring programs for KL2 scholars. Clinical and Translational Science, 3, 299-304.

Sorkness, C., Pfund, C., Ofili, E., Okuyemi, K., \& Vishwanatha, J. (2017). A new approach to mentoring for research careers: Training in the National Research Mentoring Network. BioMed Central Proceedings, 11(Suppl 12), 14.

Sorkness, C. A., Pfund, C., Asquith, P., \& Drezner, M. K. (2013). Research mentor training: Initiatives of the University of Wisconsin Institute for Clinical and Translational Research. Clinical and Translational Science, 6,256

Thomas, D. (2001). The truth about mentoring minorities: Race matters Harvard Business Review, 74(5), 98.

Valantine, H., \& Collins, F. (2015). National Institutes of Health addresses the science of diversity. Proceedings of the National Academy of Sciences USA, 112(40), 12240-12242

Wall, C. A. (2009). Faculty as change agents-reflections on my academic life. In Brown-Glaude, W. R. (Ed.), Doing diversity in higher education Faculty leaders share challenges and strategies (pp. ix-xiv). New Brunswick, NJ: Rutgers University Press.

Yarber, L., Brownson, C. A., Jacob, R. R., Baker, E. A., Jones, E., Baumann, C. ... Brownson, R.C. (2015). Evaluating a train-the-trainer approach for improving capacity for evidence-based decision making in public health. BMC Health Services Research, 15, 547. 